\title{
lodine and pregnancy - a UK cross-sectional survey of dietary intake, knowledge and awareness
}

\author{
E. Combet*, M. Bouga, B. Pan, M. E. J. Lean and C. O. Christopher \\ Department of Human Nutrition, School of Medicine, College of Medical, Veterinary and Life Sciences, University of Glasgow, \\ New Lister Building, Alexandra Parade, Glasgow G31 2ER, UK
}

(Submitted 3 July 2014 - Final revision received 25 January 2015 - Accepted 9 April 2015 - First published online 26 May 2015)

\section{Abstract}

Iodine is a key component of the thyroid hormones, which are critical for healthy growth, development and metabolism. The UK population is now classified as mildly iodine-insufficient. Adequate levels of iodine during pregnancy are essential for fetal neurodevelopment, and mild iodine deficiency is linked to developmental impairments. In the absence of prophylaxis in the UK, awareness of nutritional recommendations during pregnancy would empower mothers to make the right dietary choices leading to adequate iodine intake. The present study aimed to: estimate mothers' dietary iodine intake in pregnancy (using a FFQ); assess awareness of the importance of iodine in pregnancy with an understanding of existing pregnancy dietary and lifestyle recommendations with relevance for iodine; examine the level of confidence in meeting adequate iodine intake. A cross-sectional survey was conducted and questionnaires were distributed between August 2011 and February 2012 on local (Glasgow) and national levels (online electronic questionnaire); 1026 women, UK-resident and pregnant or mother to a child aged up to 36 months participated in the study. While self-reported awareness about general nutritional recommendations during pregnancy was high (96\%), awareness of iodine-specific recommendations was very low (12\%), as well as the level of confidence of how to achieve adequate iodine intake (28\%). Median pregnancy iodine intake, without supplements, calculated from the FFQ, was $190 \mu \mathrm{g} / \mathrm{d}$ (interquartile range $144-256 \mu \mathrm{g} / \mathrm{d}$ ), which was lower than that of the WHO's recommended intake for pregnant women $(250 \mu \mathrm{g} / \mathrm{d})$. Current dietary recommendations in pregnancy, and their dissemination, are found not to equip women to meet the requirements for iodine intake.

\section{Key words: Iodine: Pregnancy: Dietary recommendations: Awareness: Nutrition education}

Iodine is essential for the production of thyroid hormones, which are crucial for neurodevelopment in utero, in infancy and beyond. Iodine deficiency is a major public health problem affecting 1.9 billion globally, and the most preventable cause of intellectual disability ${ }^{(1)}$. This issue is not limited to developing countries, with mild maternal iodine insufficiency (classification based on median urinary iodine concentration being $50-99 \mu \mathrm{g} / 1$, according to the $\mathrm{WHO}$ criteria $^{(1)}$ ) recently shown to affect the cognitive function of the offspring, in the Avon Longitudinal Study of Parents and Children (ALSPAC) study ${ }^{(2)}$ and in the Gestational Iodine Cohort study ${ }^{(3)}$.

In the UK, the Reference Nutrient Intake for adults is $140 \mu \mathrm{g} / \mathrm{d}$, without any proposed increment for pregnant and lactating women. Meanwhile, the WHO/United Nations Children's Fund (UNICEF)/International Council for the Control of Iodine Deficiency Disorders (ICCIDD) recommended daily intake for adults is $150 \mu \mathrm{g} / \mathrm{d}$, increased to $250 \mu \mathrm{g} / \mathrm{d}$ for pregnant women $^{(1)}$. The European Food Safety Authority (EFSA) ${ }^{(4)}$ recently proposed a new reference value of adequate intake for pregnant women of $200 \mu \mathrm{g} / \mathrm{d}$. This increase is necessary to ensure that mothers have sufficient iodine to allow for increased thyroid hormone production, fetal needs and increased maternal renal clearance during this time ${ }^{(5-7)}$. Principal dietary sources of iodine include seafood and dairy products (mainly due to the iodine fortification of cattle feeds and the use of iodophores for sanitation during milking), and in some countries, iodine fortified salt or bread ${ }^{(8-10)}$. The unborn or the breastfed infant is entirely reliant on the mother for iodine supply. Young infants and pregnant or lactating mothers are the most vulnerable groups of the population because of their special requirements during these critical periods ${ }^{(11,12)}$. At present, there is no recommendation for routine iodine supplementation in the UK, unlike folic acid and vitamin D, or routine testing in pregnancy that would reflect iodine levels, unlike Fe. Instead, women rely on recommendations for a nutritionally balanced diet in pregnancy, such as those disseminated by the National Health Service (NHS, Ready Steady Baby book) and the Food Standard Agency (Eating while you are pregnant) ${ }^{(13)}$.

Abbreviations: IQR, interquartile range; T1, first trimester; T2, second trimester; T3, third trimester.

*Corresponding author: Dr E. Combet, email emilie.combetaspray@glasgow.ac.uk 
While mild iodine insufficiency has been shown in UK females of childbearing age ${ }^{(14)}$, as well as pregnant women ${ }^{(15)}$, there is no iodine prophylaxis in place, and no pregnancy-specific recommended iodine intake. According to international guidelines, mothers need to meet the recommended iodine intake, an increase of $100 \mu \mathrm{g} / \mathrm{d}$ over that of an adult, via dietary choices alone. However, general nutritional knowledge of western populations has been shown to be poor $^{(16)}$, especially when it comes to iodine-specific needs: this was true in Australia before the mandatory iodine fortification of salt and bread ${ }^{(17)}$, and remained so even after the introduction of the measure despite a slight improvement of knowledge and intake of iodine ${ }^{(18)}$. A notable exception is New Zealand, where iodine fortification and awareness measures are more common than in the UK, the US or Australia $^{(19)}$, as the problem in those countries has been noticed earlier and has been the centre of attention for research.

In the absence of prophylaxis for iodine in the UK and the need of mothers' empowerment, the aims of this study were to (1) define the dietary iodine intake of this population using a validated iodine-specific questionnaire ${ }^{(10)}$ and (2) to examine the levels of knowledge and awareness of mothers, either pregnant or with a child aged up to 36 months, regarding pregnancy-specific dietary recommendations, as well as iodine-specific requirements.

\section{Experimental methods}

The present study was conducted according to the guidelines laid down in the Declaration of Helsinki, and all procedures involving human subjects were approved by the University of Glasgow ethics committee. Consent was informed, implied and confirmed by both ticking on the questionnaire and submitting the completed questionnaire. A sample size calculation based on an estimated $33 \%$ prevalence of provision of iodine-related information during pregnancy ${ }^{(20)}$, a 95\% CI, a design effect of two and an absolute precision of $5 \%$ resulted in a sample size of at least 680 women. To allow for subgroup comparisons, a sample size of at least $n 823$ was required ( $\alpha=0.05,1-\beta=0 \cdot 8$ ), based on the prevalence of iodinerelated information cited above, and to detect a difference in prevalence of low iodine intake of $15 \%$ between groups ${ }^{(21)}$.

\section{Study design and participants}

The study was cross-sectional, and the participants were recruited (1) using convenient sampling in Greater Glasgow, and (2) via distribution of an online version of the questionnaire in the UK, between July 2011 and February 2012. In greater Glasgow, both public and private locations were used for recruitment, including mothers and toddler groups, pregnancy classes, shops, libraries, community playgroups, public parks, playgrounds and indoor soft play areas. Recruitment posters were displayed with the study team contact detail as well as a link to the electronic form of the survey. In parallel, women were approached as they entered or exited the facility/shop. The online version of the questionnaire was posted on parenting websites and forums (mumsnet.com, netmums.com, bounty.com, pregnancyforum.org.uk and Gurgle.com) as well as regional Gumtree groups throughout the UK, parenting Facebook groups (Single Mums UK, West of Scotland Birth Support Group, Teenage Mums, Young Mums, British Mum and Toddler Group and North London Mums) and via Twitter. To be eligible, participants had to be women residing in the UK (England, Scotland, Northern Ireland or Wales) who were either pregnant or mother to a child aged from 0 to 36 months.

\section{Questionnaire design and data collection}

Data were collected anonymously through questionnaires employing qualitative and semi-quantitative measures. The questionnaire was validated before use for face value and content (content validation was carried out independently by three subject experts, assessing the representativeness of the items, while face validation was carried out by five lay contributors, assessing presentation, phrasing and clarity of instructions). The same questionnaire was used locally and online. It consisted of four sections.

The first section focused on participants' socio-demographic characteristics (age, ethnicity and education), details of specific dietary habits (veganism, vegetarianism, lactose intolerance and other specific requirements) and existence of thyroid condition and lifestyle habits during pregnancy (alcohol and tobacco consumption). It also included questions regarding the participant's current/most recent pregnancy (due date, parity, age of last child and whether the pregnancy was planned) and breastfeeding intentions.

The second part of the questionnaire assessed participants' awareness of pregnancy-specific dietary recommendations, their usual source of information and level of understanding of these recommendations. A 7-point Likert scale assessed how closely participants followed dietary recommendations in pregnancy and the likelihood of ceasing the consumption of dairy and seafood in case of any doubt regarding the safety of consuming the item.

The third section of the questionnaire included a validated iodine-specific $\mathrm{FFQ}^{(10)}$. A question focused on pregnancy vitamins and supplements, evaluating frequency of intake (every day or some days) and pregnancy period when supplements were taken (first trimester (T1) only, or throughout pregnancy), along with brand names.

Multiple choice and open questions investigated the reasons motivating any dietary changes during pregnancy, as well as awareness about micronutrient requirements and confidence about the level of information received to achieve requirements.

The final section of the questionnaire assessed knowledge about iodine (food sources, and consequences of maternal deficiency on the offspring via closed and multiple choice questions) and confidence in how to achieve the recommended iodine intake (7-point Likert scale).

\section{Data analysis}

Data were entered manually in a database, or downloaded from the University of Glasgow server hosting the electronic survey. 
The overall database was cleaned, and descriptive statistics were calculated for all outcome variables. Open text questions were reviewed for key themes. Results were expressed as: mean and standard deviation for parametric continuous data; median and interquartile range (IQR) for non-parametric continuous data; mode and frequencies for categorical data. The FFQ was analysed as described by Combet $\&$ Lean $^{(10)}$, and dietary iodine intake was reported as a single value for the whole pregnancy. Supplemental iodine intake was defined according to the brand name, the frequency ('every day', or 'some days' estimated as every other day). Since supplemental iodine intake was reported either throughout the pregnancy or in T1 only, total iodine intake was calculated for $\mathrm{T} 1$, and the second and third trimesters (T2 and T3) separately.

The chosen cut-off for adequate iodine intake was the WHO recommendation for pregnant women $(250 \mu \mathrm{g} / \mathrm{d})^{(1)}$ and not that of the UK Reference Nutrient Intake ${ }^{(22)}$; this choice was motivated by the fact that the UK Reference Nutrient Intake has not been revised since 1991, despite evidence that iodine requirement increases during pregnancy ${ }^{(1)}$. Comparison between groups was carried out using the $\chi^{2}$ test for categorical data, the Student's $t$ test for parametric continuous data, or the Mann-Whitney $U$ test for continuous non-parametric data.

A multinomial logistic regression analysis was performed for the prediction of dietary iodine intake, total iodine intake (dietary intake plus supplements) during T1 and during T2 and T3. The categories for iodine intake were defined as: less than $140 \mu \mathrm{g} / \mathrm{d}$, which is the cut-off for adequacy in adults; $140-250 \mu \mathrm{g} / \mathrm{d}$ which is between the cut-off of adequacy for adults and the recommended intake for pregnant women; and $>250 \mu \mathrm{g} / \mathrm{d}^{(1)}$. Because iodine intake might be affected by a range of factors (socio-economic and existing knowledge of the iodine importance), relevant independent variables were included in the model. These were age, education level (school, college or university), ethnicity (British, other white groups, other ethnic groups), smoking status, having received any information on iodine or $\mathrm{Ca}$, and being aware of the importance of iodine for healthy development of the unborn baby. The statistical software SPSS version 21.0 (IBM Corporation) was used.

\section{Results}

\section{Participants' characteristics}

A total of 1026 women took part in the survey, 30\% of whom were pregnant at the time of the study. The median age of participants was 32 (IQR 29-36) years with their youngest child of a median age of 14 (IQR 6-25) weeks. Most had one child (51\%), $37 \%$ had two or more children while $12 \%$ were pregnant with first child. Most pregnant women were in T3 of pregnancy ( $51 \%$ ). Most pregnancies ( $80 \%)$ were planned and discovered at 4 (IQR 4-6) weeks. The majority of participants were White British (87\%), and had degree level education or more (62\%) (Table 1).

\section{General nutritional awareness during pregnancy}

The majority of women (96\%) reported awareness of dietary and lifestyle recommendations specific for pregnancy, such
Table 1. Basic characteristics of participants

(Number of participants and percentages; median and interquartile ranges (IQR))

\begin{tabular}{|c|c|c|}
\hline Demographic data & $n$ & $\%$ \\
\hline \multicolumn{3}{|l|}{ Maternal age (years) } \\
\hline Median & \multirow{2}{*}{\multicolumn{2}{|c|}{$\begin{array}{c}32 \\
29-36\end{array}$}} \\
\hline IQR & & \\
\hline \multicolumn{3}{|l|}{ Babies' age (weeks) } \\
\hline Median & \multirow{2}{*}{\multicolumn{2}{|c|}{$\begin{array}{c}14 \cdot 0 \\
6-25\end{array}$}} \\
\hline IQR & & \\
\hline \multicolumn{3}{|l|}{ Ethnicity } \\
\hline White British & 887 & 87 \\
\hline Other White & 83 & 8 \\
\hline Other ethnic groups & 56 & 6 \\
\hline \multicolumn{3}{|l|}{ Education } \\
\hline School level & 186 & 18 \\
\hline College level & 206 & 20 \\
\hline $\mathrm{BSc} / \mathrm{MSc} / \mathrm{PhD}$ & 625 & 62 \\
\hline \multicolumn{3}{|c|}{ Use of supplements (iodised/non-iodised) } \\
\hline Throughout pregnancy & $305 / 209$ & $30 / 20$ \\
\hline First trimester only & $87 / 199$ & $8 / 19$ \\
\hline Never & 101 & 10 \\
\hline Pregnancy & 305 & 30 \\
\hline First trimester & 67 & 22 \\
\hline Second trimester & 79 & 26 \\
\hline Third trimester & 154 & 51 \\
\hline Planned pregnancies & 807 & 80 \\
\hline \multicolumn{3}{|l|}{ Number of children } \\
\hline 0 (Expecting first) & 123 & 12 \\
\hline 1 & 520 & 51 \\
\hline 2 or more & 383 & 37 \\
\hline Smokers & 100 & 10 \\
\hline
\end{tabular}

as those currently provided in the Ready Steady Baby NHS book or websites on pregnancy diet (such as the Food Standard Agency 'Eating while you are Pregnant') ${ }^{(13)}$. The main sources of information were the internet $(65 \%)$ and books and magazines (62\%), followed by written and oral advice from their doctor (59 and 52\%, respectively), and family and friends (43\%). Only $16 \%$ received information during antenatal classes. The majority (90\%) were aware of recommendations about smoking, alcohol and caffeine. However, a third $(34 \%)$ of smokers continued smoking during pregnancy, and $14 \%$ of the total population did not stop or limit alcohol consumption.

Most of the respondents found the dietary recommendations easy to understand (92\%), and easy to follow (83\%). There was a high level of awareness for most dietary recommendations for pregnancy with the exception of the recommendation for vitamin A intake (Table 2). Confusion over the recommendations was reported by $47 \%$ ( $n$ 482) of the overall population, with $41 \%$ ( $n$ 419) seeking clarification or further information. The internet was the main source of complementary information (82\%), followed by Health Care Professionals (18\%), books (15\%), and family and friends (8\%).

Information provision about specific nutrients (folic acid, $\mathrm{Fe}$, iodine, $\mathrm{Ca}$ and vitamins $\mathrm{A}$ and $\mathrm{D}$ ) varied. All the participants $(100 \%)$ had heard about folic acid, and most had heard about $\mathrm{Fe}(96 \%)$ in pregnancy. However, $64 \%$ of the mothers had never received information about iodine, and only $11 \%$ had heard about iodine from a health care professional (Table 3 ). Only $12 \%$ reported that information 
Table 2. Pregnancy dietary recommendations ${ }^{*}$ - self-reported awareness and confusion

\begin{tabular}{lcc}
\hline & Number of participants & \% of total sample \\
\hline Self-reported awareness & & \\
Stop smoking & 1012 & 99 \\
Stop/limit alcohol & 1012 & 99 \\
Limit caffeine & 961 & 94 \\
Avoid certain foods due to bacterial infection risk & 940 & 92 \\
Avoid raw meat, fish or poultry & 912 & 89 \\
Avoid certain fish due to heavy metals/toxins & 864 & 84 \\
Wash all fruit and vegetables & 848 & 83 \\
Limit oily fish to two portions per week & 748 & 73 \\
Limit vitamin A intake & 592 & 58 \\
Any other recommendations† & 134 & 13 \\
Self-reported confusion in recommendations & & 19 \\
Avoid certain foods due to bacterial infection risk & 192 & 16 \\
Limit vitamin A intake & 167 & 10 \\
Avoid certain fish due to heavy metals/toxins & 99 & 10 \\
Limit oily fish to two portions per week & 99 & 7 \\
Limit caffeine & 71 & 6 \\
Stop/limit alcohol & 65 & 5 \\
Avoid raw meat, fish or poultry & 49 & 4 \\
Any other recommendation† & 37 & 3 \\
Wash all fruit and vegetables & 26 & 1 \\
Stop smoking & 7 & \\
Was extra information sought in case of confusion? & & 41 \\
Yes & 419 & 14 \\
No & 140 & 33 \\
N/A & 334 & 25 \\
Did the extra information provide clarification? & & 7 \\
Yes & 260 & \\
No & 73 & \\
Not sure & & \\
\hline
\end{tabular}

N/A, not applicable.

${ }^{*}$ Recommendations available in the National Health Service Ready Steady Baby book, and the Food Standard Agency 'Eating while you are pregnant' ${ }^{\text {(13) }}$.

†Folic acid, cheese, eggs, nuts, vitamin D.

received was sufficient for iodine, followed by 50 and $49 \%$ for vitamin D and vitamin A (Table 4).

\section{Changes in dietary habits during pregnancy}

Only a minority of the participants were vegetarian (9\%), vegan $(1 \%)$ or lactose intolerant $(1 \%)$, and $6 \%$ of the mothers reported an existing thyroid condition. Salt was added to food by $48 \%$ of women (at the table or during cooking).

Most reported increased fruit consumption during pregnancy (49\%). The majority reported similar levels of intake for milk, cheese, yoghurts, eggs, oily fish, white fish, meat, brassicas, other vegetables, soy products and grains, cereals and pasta during pregnancy, compared to intake levels before pregnancy (Table 6). Increased intakes for milk, cheese and yoghurt were reported by 43, 19 and 25\%, respectively (Table 5).

Nearly half (44\%) of changes in dietary patterns were motivated by recommendations and advice specific for food and diet during pregnancy. Foods most often mentioned were fruit (8\%), fish (9\%), cheese (6\%) and milk (6\%). Morning sickness was the reason motivating $30 \%$ of the dietary changes reported, mostly meat, fish and milk. Other reasons were heartburn (21\%) and change in taste (7\%).

High adherence to dietary recommendation was reported (mode 6, frequency 33\% on a 7-point Likert scale), which was reflected in choices to withdraw from consuming a particular type of food, if the safety of consuming the item could not be confirmed (cheese: mode 7 , frequency $25 \%$; fish: mode 7 , frequency $31 \%$ ).

Table 3. Sources of information for specific nutrients (respondents could select several options).

\begin{tabular}{lccccc}
\hline \multicolumn{5}{c}{ Source of information (\% of total population) } \\
\cline { 2 - 6 } & Never heard of & Doctor, midwife or health visitor & Family and friends & Books and magazines & Internet \\
\hline Folic acid & 0 & 88 & 39 & 47 & 40 \\
Iron & 4 & 71 & 24 & 32 & 27 \\
lodine & 64 & 11 & 25 & 33 & 25 \\
Calcium & 11 & 49 & 14 & 29 & 24 \\
Vitamin D & 19 & 44 & 12 & 29 & 25 \\
Vitamin A & 24 & 42 & & & \\
\hline
\end{tabular}


Table 4. Perceived sufficiency of the information received regarding specific nutrients in order to make decisions on dietary modification to achieve adequate intake/levels in pregnancy

\begin{tabular}{lccc}
\hline & \multicolumn{3}{c}{$\begin{array}{c}\text { Was information sufficient? } \\
\text { (\% of total population) }\end{array}$} \\
\cline { 2 - 4 } & No & Yes & Not sure \\
\hline Folic acid & 5 & 92 & 4 \\
Fe & 13 & 76 & 11 \\
lodine & 54 & 12 & 34 \\
Ca & 21 & 64 & 16 \\
Vitamin D & 30 & 49 & 22 \\
Vitamin A & 28 & 50 & 22 \\
\hline
\end{tabular}

\section{lodine intake during pregnancy}

Without taking supplements into consideration, median dietary iodine intake in pregnancy was estimated at 190 (IQR 144-256) $\mu \mathrm{g} / \mathrm{d}$, with $74 \%$ consuming below the recommended $250 \mu \mathrm{g}$ iodine/d, and $55 \%$ below the proposed $200 \mu \mathrm{g} / \mathrm{d}$ threshold (Fig. 1). The highest contributors to iodine intake were milk ( $40 \%$, contributing toward 75 (IQR 42-113) $\mu \mathrm{g} / \mathrm{d}$, followed by other dairy products (31\%) and fish (24\%).

Daily iodine intake from foods was not different between women taking supplements or not $(P=0 \cdot 36)$. However, taking supplements significantly increased total iodine intake, both during T1 (237 (IQR 163-320) v. 190 (IQR 144-256) $\mu \mathrm{g} / \mathrm{d}$, non-supplemented) and during T2 and T3 (223 (IQR 157-309) v. 190 (IQR 144-256) $\mu \mathrm{g} / \mathrm{d}$, nonsupplemented) $(P<0 \cdot 001)$.

\section{Knowledge of iodine-rich foods and awareness of its role during pregnancy}

Knowledge of iodine-rich foods was low, with $56 \%$ unable to identify any iodine-rich food and a majority wrongfully believing that dark green vegetables (54\%) and table salt (21\%) (which is not fortified in the UK) are iodine-rich foods. Milk and yoghurt were only recognised as iodine-rich sources by 9 and $6 \%$ of the population, respectively, with fish faring slightly better (33\% for oily fish and 14\% for white fish).
While $84 \%$ were unaware that, during pregnancy, iodine from the diet is important for healthy development of the unborn baby, most mothers (85\%) agreed or strongly agreed they would attempt to increase their iodine intake if made aware of the impact of iodine deficiency (7-point Likert scale). Mothers (72\%) however, disagreed or strongly disagreed that they were confident on how to achieve an adequate iodine intake in pregnancy (7-point Likert scale).

\section{Impact of dietary advice and awareness on iodine intake}

Receiving any advice on iodine ( $n 371,36 \%$ ) had no impact on iodine intake from food only $(P=0 \cdot 218)$, or intake from food and supplements in the T1 of pregnancy $(P=0 \cdot 106)$. However, intakes were marginally higher in T2 and T3 for those who had received information $(P=0.049)$ (Table 6). Those who perceived the advice to be sufficient ( $n$ 112, $12 \%$ ) had no higher iodine intake from either food only during the whole pregnancy $(P=0.974)$, or from food and supplements during T1 $(P=0.402)$ or during T2 and T3 ( $P=0.530)$.

Receiving any advice on $\mathrm{Ca}(n$ 911, 89\%) increased iodine intake from food only $(P=0.009)$, intake from food and supplement in T1 of pregnancy $(P=0.001)$, and intake in T2 and T3 $(P=0.001)$ (Table 6). Participants who perceived the Ca advice to be sufficient ( $n$ 610, 64\%), had a higher intake of iodine from food only $(P=0 \cdot 014)$, and food and supplement in T1 $(P<0 \cdot 001)$, as well as T2 and T3 $(P<0 \cdot 001)$.

Awareness of the impact of low iodine during pregnancy on healthy development of the unborn baby ( $n$ 165, 16\%) did not lead to significantly higher iodine intake, with or without supplementation (food only $P=0.782$, from food and supplement in T1 $P=0 \cdot 905$, or T2 and T3 $P=0 \cdot 660$ ).

\section{Other factors affecting iodine intake in pregnancy}

Planned pregnancies, salt usage and smoking did not impact on iodine intake (with or without supplement). However, education level had an impact on dietary iodine intake $(P=0 \cdot 009)$ and total iodine intake in T2 and T3 $(P=0 \cdot 010)$, with higher

Table 5. Reported changes in the intake of specific foods during pregnancy

\begin{tabular}{|c|c|c|c|c|c|c|c|c|}
\hline & \multicolumn{2}{|c|}{$\begin{array}{l}\text { Not consumed } \\
\text { during or before } \\
\text { pregnancy }\end{array}$} & \multicolumn{2}{|c|}{$\begin{array}{l}\text { Decreased or } \\
\text { stopped } \\
\text { consumption }\end{array}$} & \multicolumn{2}{|c|}{ As before } & \multicolumn{2}{|c|}{ Increased } \\
\hline & $n$ & $\%$ & $n$ & $\%$ & $n$ & $\%$ & $n$ & $\%$ \\
\hline Milk & 51 & 5 & 53 & 5 & 465 & 47 & 429 & 43 \\
\hline Cheese & 25 & 3 & 171 & 17 & 609 & 61 & 193 & 19 \\
\hline Yoghurts & 54 & 5 & 65 & 7 & 627 & 63 & 246 & 25 \\
\hline Eggs & 46 & 6 & 255 & 26 & 609 & 61 & 89 & 9 \\
\hline Oily fish & 137 & 14 & 268 & 27 & 494 & 50 & 96 & 10 \\
\hline White fish & 121 & 12 & 114 & 12 & 674 & 68 & 79 & 8 \\
\hline Meat & 67 & 7 & 103 & 10 & 739 & 72 & 106 & 11 \\
\hline Brassicas & 48 & 5 & 65 & 6 & 651 & 64 & 205 & 20 \\
\hline Other vegetables & 8 & 1 & 38 & 4 & 633 & 63 & 324 & 32 \\
\hline Fruits & 7 & 1 & 36 & 4 & 467 & 47 & 491 & 49 \\
\hline Soya products & 376 & 40 & 98 & 10 & 457 & 48 & 22 & 2 \\
\hline Bread, rice, cereals, pasta & 3 & 0 & 33 & 3 & 703 & 70 & 261 & 26 \\
\hline
\end{tabular}



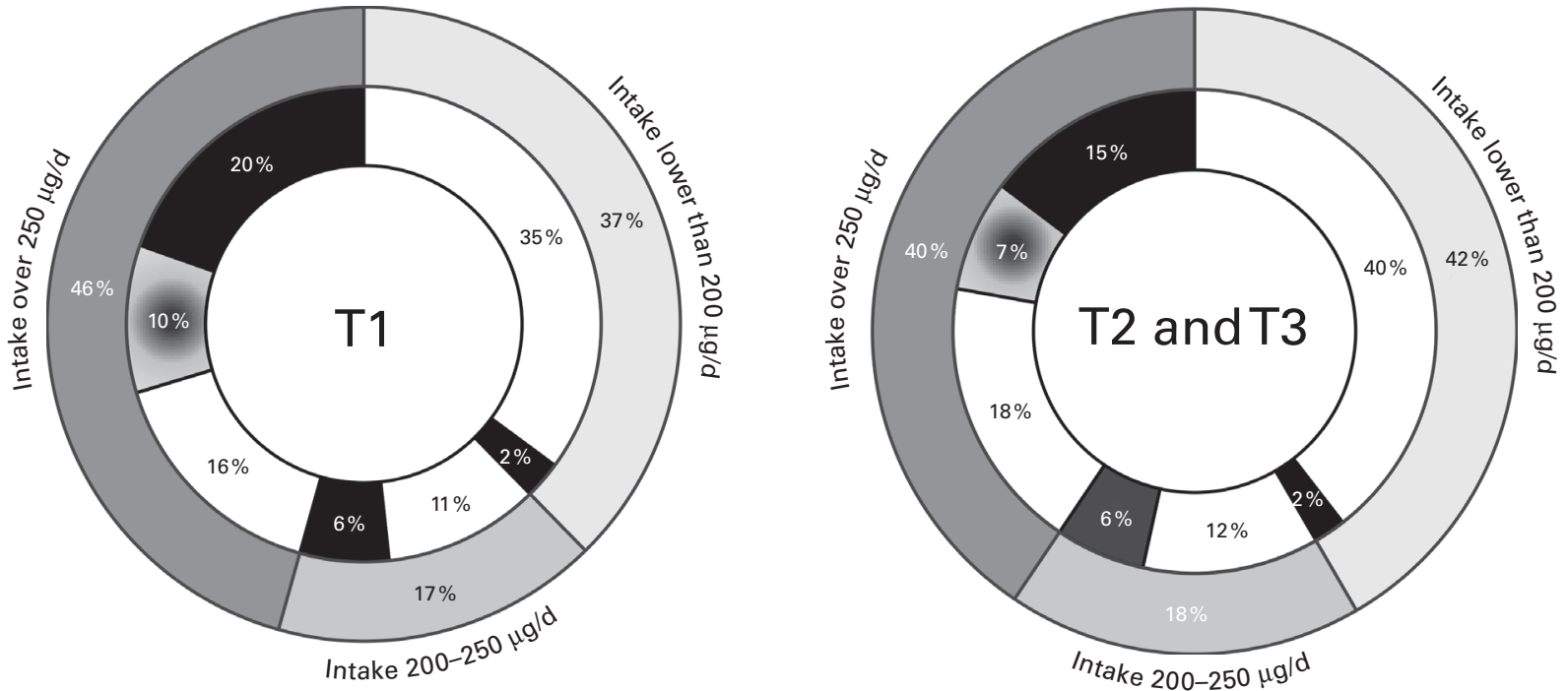

Fig. 1. lodine intake in pregnancy in 1026 women, recruited in the UK, August 2011-February 2012, according to set levels of adequacy from WHO/United Nations Children's Fund/International Council for the Control of lodine Deficiency Disorders ${ }^{(1)}(>250 \mu \mathrm{g} / \mathrm{d})$ and European Food Safety Authority panel on Dietetic Products, Nutrition and Allergies ${ }^{(4)}(>200 \mu \mathrm{g} / \mathrm{d})$. Supplement use for each sector of iodine intake is depicted on the inside circle. Only $26 \%$ during first trimester (T1) and $25 \%$ during second (T2) and third trimester (T3) reached the $250 \mu \mathrm{g}$ threshold through diet only (regardless whether they consumed iodised supplements). The new proposed level of adequate intake $(200 \mu \mathrm{g} / \mathrm{d})$ was reached by $63 \%$ during T1 (26\% thanks to supplements) and $58 \%$ during T2 and T3 ( $21 \%$ thanks to supplements). $\mathbf{\square}$, With iodised supplements; $\square$, without iodised supplements; $\square$, dietary intake sufficient, and also took iodised supplements.

intake generally associated with higher education levels. Total iodine intakes in T2 and T3 were also higher in older women compared to younger $(P=0.036)$.

The multinomial logistic regression models (Table 7) for iodine intake from the diet alone, total iodine intake in T1, and $\mathrm{T} 2$ and $\mathrm{T} 3 \mathrm{had}$ an improved fit, compared to the empty models (models with no predictor variables) $(P=0.05,0.02$ and $0 \cdot 01$, respectively), with low pseudo $R^{2}$ values (below 0.05). Receiving information about Ca significantly lowered the odds of having a low iodine intake $(<140 \mu \mathrm{g}$ compared to $>250 \mu \mathrm{g} / \mathrm{d}$ ) at any stage of pregnancy, from diet alone, or taking supplements in consideration. It also decreased the odd of having a total iodine intake between $140-250 \mu \mathrm{g}$ compared to $>250 \mu \mathrm{g}$, in $\mathrm{T} 1$, and $\mathrm{T} 2$ and $\mathrm{T} 3$. Those who had ever been informed about iodine had surprisingly higher odds of having a low total iodine intake $(<140 \mu \mathrm{g}$ compared to $>250 \mu \mathrm{g} / \mathrm{d}$ ) in T1, T2 and T3. Being aware of the importance of iodine had no predictive value in the models. Education did not consistently predict iodine intake, with achieving school education predicting higher odds of lower total iodine intake $(<140 \mu \mathrm{g}$ compared to $>250 \mu \mathrm{g} / \mathrm{d})$ in $\mathrm{T} 2$ and $\mathrm{T} 3$.

\section{Discussion}

\section{Principal study findings}

Dietary iodine intake in pregnancy was lower than the WHO's recommendation of $250 \mu \mathrm{g} / \mathrm{d}$, even when supplemental iodine was taken in consideration. This is consistent with recent findings in pregnant women in the South East of the $\mathrm{UK}^{(15)}$. Despite generally high self-reported awareness of existing dietary and lifestyle recommendations for pregnancy, iodine awareness and knowledge were low among the UK

Table 6. lodine intake with and without supplements in the whole group, in women having received advice on iodine, advice on calcium and in women who were aware of iodine importance during pregnancy $\dagger$

(Medians and interquartile ranges (IQR))

\begin{tabular}{|c|c|c|c|c|c|c|c|c|}
\hline \multirow[b]{2}{*}{ lodine intake $(\mu \mathrm{g} / \mathrm{d})$} & \multicolumn{2}{|c|}{ All women (n 1026) } & \multicolumn{2}{|c|}{$\begin{array}{l}\text { Women who received } \\
\text { iodine advice ( } n 371)\end{array}$} & \multicolumn{2}{|c|}{$\begin{array}{l}\text { Women who } \\
\text { received } \mathrm{Ca} \\
\text { advice }(n 911)\end{array}$} & \multicolumn{2}{|c|}{$\begin{array}{l}\text { Women aware of } \\
\text { iodine importance during } \\
\text { pregnancy }(n 165)\end{array}$} \\
\hline & Median & IQR & Median & IQR & Median & IQR & Median & IQR \\
\hline Dietary iodine only & 190 & $144-256$ & 185 & $136-261$ & $193^{*}$ & $146-259$ & 193 & $138-267$ \\
\hline Total (T1)‡ & 237 & $163-320$ & 240 & $170-320$ & $242^{*}$ & $167-324$ & 241 & $152-339$ \\
\hline Total (T2 and T3) & 223 & $157-163$ & $228^{*}$ & $165-309$ & $228^{*}$ & $160-312$ & 220 & $149-317$ \\
\hline
\end{tabular}

T1, first trimester; T2, second trimester; T3, third trimester.

* lodine intake values were significantly different from the rest of the group $(P<0.05$; Mann-Whitney $U$ test).

† Advice received could be from any source (doctors, midwives or health visitors, family and friends, books and magazines or from the internet).

$\ddagger$ Total indicates iodine from food and supplement sources. 
mothers (pregnant or with children aged 0-36 months). This is in agreement with those of mothers in other countries, where a large gap still exists for iodine awareness and knowledge ${ }^{(16,17,23)}$.

Iodine is crucial during pregnancy and the first few months of child life, to ensure adequate brain development, driven by the thyroid hormones. Mild insufficiency has been linked to measurable cognitive decline in school performance and cognition $^{(2,24)}$. A recent meta-analysis of twenty-four studies on iodine and intellectual disability in young children concluded that iodine insufficiency leads to mental impairment, and this is apparent when comparing the intelligence quotient score of children of iodine-deficient mothers, which is 7.4 points lower compared to that of children of iodinereplete mothers ${ }^{(24)}$. Although many of the studies included in the review suffered from poor design, with only a few randomised controlled trials, there is some evidence that iodine deficiency impacts on cognitive function. In particular, supplementation with $300 \mu \mathrm{g}$ iodine during T1 of pregnancy led to improved cognitive development in the offspring ${ }^{(25)}$. It is therefore a major concern that the majority of (recently) pregnant women in the UK are unaware of the importance of iodine, when the evidence points toward inadequate iodine status in women ${ }^{(14,26,27)}$ in a country with no iodine prophylaxis.

Awareness is a means of empowerment in any case of choice. While the messages about folic acid and Fe were heard (from various sources) and perceived to be sufficient, mothers were not confident about their iodine intake, in terms of dietary sources or how to meet the adequate levels for pregnancy, in accordance with recent Australian findings ${ }^{(17)}$.

The UK has been listed as the top eighth iodine-deficient country in the world ${ }^{(28)}$. Participants of the present study had an average daily iodine intake of $190 \mu \mathrm{g} / \mathrm{d}$ from food only, which is lower than the recommended $250 \mu \mathrm{g} / \mathrm{d}$ during pregnancy ${ }^{(1)}$, and the newly proposed $200 \mu \mathrm{g} / \mathrm{d}$ EFSA threshold $^{(4)}$. In fact, through their diet, only $26 \%$ of women were able to meet the $250 \mu \mathrm{g} / \mathrm{d}$ recommendation, and $45 \%$ the $200 \mu \mathrm{g} / \mathrm{d}$ mark. Milk and other dairy products were the main contributors to iodine intake, in agreement with the data of $1997-8^{(29)}$.

Taking supplements containing iodine in consideration (consumed by $38 \%$ of the participants), the daily iodine intake was $237 \mu \mathrm{g} / \mathrm{d}$ in $\mathrm{T} 1$ and $223 \mu \mathrm{g} / \mathrm{d}$ in $\mathrm{T} 2$ and T3. Use of iodised supplements helped women to achieve an adequate iodine intake. It has been shown that nutritional knowledge is strongly associated with the use of supplements during pregnancy ${ }^{(30)}$. Iodine supplementation given to pregnant women with mild deficiencies appeared to benefit subsequent child development ${ }^{(31)}$. However, in the present study less than half of the participants were taking iodine containing supplements, in line with previous findings ${ }^{(26,32-35)}$. This is despite the fact that popular prenatal multivitamin brands do contain iodine; but in practice many women take single folic acid supplement or a formulation not labelled for pregnancy or not containing iodine ${ }^{(26)}$.

While healthcare professionals are well placed to impart advice and help effect dietary change, studies indicate that 
women's dietary patterns change little during pregnancy ${ }^{(36-38)}$. The present results are in agreement with this observation, and consumption levels of milk, dairy and fish were mostly unchanged during pregnancy, despite the increased daily requirement for iodine. Similarly, another UK cohort study examining dietary patterns before and at two points during pregnancy showed that the median weekly consumption of iodine-rich foods did not change significantly ${ }^{(39)}$.

\section{Strengths and weaknesses of the study}

Deprivation, defined by income or education, has been shown to be associated with increased risks of insufficient micronutrient intake ${ }^{(40)}$ and poorer quality diet ${ }^{(41)}$. In the present study, levels of deprivation based on postcodes could not be used, due to differences between the English, Scottish, Northern Irish and Welsh deprivation scoring. Women of higher socioeconomic status (defined by education, income, and/or occupation) are also more likely to consume iodinerich foods, such as fish and dairy ${ }^{(42)}$. In the light of this situation, it appears that women of lower socioeconomic status may be less likely to achieve sufficient iodine intake during pregnancy.

The present study used a FFQ ${ }^{(10)}$ involving an element of recall, which may have led to a loss of accuracy and overestimation of the nutrient intake ${ }^{(43)}$. The convenient sampling method used locally, and the electronic recruitment used nationally have yielded a large sample size. A majority (68\%) of the participants were recruited online. While this was considered to be a limitation in the past ${ }^{(44)}$, the wide access to the internet in the UK renders online recruitment a successful method in health research $^{(45,46)}$. The study participants were generally quite knowledgeable about health, had a high rate of planned pregnancies (80 v. 55\% in the UK population ${ }^{(47)}$ ) and were well-educated. This feature appears to be common in survey-based studies, but surprisingly the results show a poor knowledge about iodine even amongst educated women.

\section{Possible mechanisms and implications for clinicians and policy makers}

Achieving an intake of $250 \mu \mathrm{g} / \mathrm{d}$ (or $1750 \mu \mathrm{g} /$ week) is challenging and requires consumption of high amounts of dairy and seafood. For illustrative purpose, $250 \mu \mathrm{g} / \mathrm{d}^{(1)}$ (or $1750 \mu \mathrm{g} /$ week) would mean consuming all of the following: milk in cereals once a day, milk in drinks (such as tea, coffee) three times a day, two yogurts per day, one dairy-based dish or pudding per day, cheese twice a day, white sea fish twice a week and oily fish once a week (based on the average iodine content of these foods ${ }^{(48)}$ ). However, receiving information about $\mathrm{Ca}$ and iodine during pregnancy, along with a higher education level, predicted sufficient iodine intake; there is hence scope for improved dietary recommendations to address the present iodine insufficiency in this vulnerable group.

Helping pregnant women with resources which ensure causal links between iodine and fetal development may increase the motivation for behavioural change ${ }^{(49)}$, as the present study has also observed. The Health Belief Model encompasses this idea. Perceived threats to health can alter behaviour if the individual is confident of carrying out the change; there is an understanding that changed actions will reduce the susceptibility or severity of a health condition, and that motivating factors outweigh the barriers that stand in the way of implementing the behavioural change ${ }^{(50)}$.

There is in the UK no guideline on iodine supplementation for mothers during pregnancy or lactation, in contrast to the USA and Canada ${ }^{(51)}$. Such a supplementation during pregnancy and lactation is endorsed by the WHO, the UNICEF and the ICCIDD for iodine-deficient countries without universal salt iodisation, such as the $\mathrm{UK}^{(52)}$. There is a sustained debate on the ethical implication of a randomised controlled trial of iodine supplementation in pregnancy ${ }^{(53,54)}$, in parallel with concerns over the conflicting message that salt iodisation would convey ${ }^{(55)}$. A recent review of the Scientific Advisory Committee on Nutrition published their position statement on iodine and health ${ }^{(56)}$, highlighting existing gaps in the evidence base. The present study made an attempt to fill some gaps in evidence on dietary and supplemental intakes of iodine in pregnancy, and underscore a greater understanding of mothers' knowledge and awareness of recommendations relevant to iodine in pregnancy.

\section{Unanswered questions and future research}

Many pregnancies remain unplanned in the UK (approximately $55 \%$ planned) and in other high-income countries (France, Spain, Japan and the USA) ${ }^{(47)}$. Iodine prophylaxis in the peri-conception stage requires further considerations. A stronger evidence-base is required in order to set thresholds for adequacy of iodine intake during and before pregnancy, with careful consideration of iodine uptake and homeostasis as a function of iodine stores.

A recent systematic review concluded that women in developed countries are not nutritionally well-educated, specifically about nutrition during pregnancy ${ }^{(57)}$. The iodine awareness, knowledge and perception of mothers in the UK were high for general recommendations during pregnancy, but low for iodine. Therefore health campaigns, fortification, supplementation and nutrition education should be seriously considered. It is unclear whether any of these strategies will be successful, in the context of the present UK food landscape and dietary habits. We have previously shown that the terminology used to define concepts of nutritional balance is commonly misunderstood by the public ${ }^{(58)}$. In addition to providing causal links, dietary recommendations should be accurate and simple to understand, and give practical advice which is easy to follow. Consistency in the advice provided (by healthcare professionals, websites and books) is essential, to avoid misinterpretations and misleading messages. The current debate on the next required step for iodine prophylaxis in the UK should not ignore the fact that the impact of any intervention will be blunted if the current lack of awareness and knowledge is not tackled first. There are significant 
differences between awareness of exact requirements at population level, awareness of the need to take supplements (which currently only applies to folic acid in the UK) and awareness of the importance of a nutrient during a crucial stage in the life of women; the present research problem needs further investigations using a more qualitative approach on a global scale.

\section{Acknowledgements}

C. O. C. was in receipt of a scholarship from the Rank Prize Funds.

The authors declare there are no conflicts of interest.

The authors' contributions are as follows: E. C. designed and supervised the study, with input from C. O. C. and M. E. J. L; C. O. C., M. B. and B. P. collected the data and contributed to its analysis; E. C. and M. B. prepared the manuscript, with input from all co-authors. All authors raed and approved the final version of the manuscript.

\section{References}

1. WHO/UNICEF/ICCIDD (2007) Assessment of Iodine Deficiency Disorders and Monitoring their Elimination. A Guide for Programme Managers, 3rd ed. Geneva: WHO.

2. Bath SC, Steer CD, Golding J, et al. (2013) Effect of inadequate iodine status in UK pregnant women on cognitive outcomes in their children: results from the Avon Longitudinal Study of Parents and Children (ALSPAC). Lancet 382, 331-337.

3. Hynes KL, Otahal P, Hay I, et al. (2013) Mild iodine deficiency during pregnancy is associated with reduced educational outcomes in the offspring: 9-year follow-up of the gestational iodine cohort. J Clin Endocrinol Metab 98, $1954-1962$.

4. EFSA Panel on Dietetic Products, Nutrition and Allergies (2014) Scientific Opinion on Dietary Reference Values for iodine. EFSA J 12, 3660.

5. Andersson M \& Zimmerman M (2010) Influence of iodine deficiency and excess on thyroid function tests. In Thyroid Function Testing, pp. 45-69. New York: Springer US.

6. Zimmermann MB, Jooste PL \& Pandav CS (2008) Iodinedeficiency disorders. Lancet 372, 1251-1262.

7. Ritchie L \& King J (2008) Nutrient recommendations and dietary guidelines for pregnant women. In Nutrition and Health: Handbook of Nutrition and Pregnancy [CJ LammiKeefe, SC Couch and EH Philipson, editors]. Totowa, NJ: Humana Press.

8. Zimmermann MB (2009) Iodine deficiency. Endocr Rev 30, 376-408.

9. Alvarez-Pedrerol M, Ribas-Fitó N, García-Esteban R, et al. (2010) Iodine sources and iodine levels in pregnant women from an area without known iodine deficiency. Clin Endocrinol 72, 81-86.

10. Combet E \& Lean MEJ (2014) Validation of a short food frequency questionnaire specific for iodine in UK females of childbearing age. J Hum Nutr Diet 27, 599-605.

11. Delange F (2007) Iodine requirements during pregnancy, lactation and the neonatal period and indicators of optimal iodine nutrition. Public Health Nutr 10, 1571-1580, discussion 1581-1573.

12. Ordookhani A, Pearce EN, Hedayati M, et al. (2007) Assessment of thyroid function and urinary and breast milk iodine concentrations in healthy newborns and their mothers in Tehran. Clin Endocrinol (Oxf) 67, 175-179.

13. Food Standards Agency (2002) Eating While You are Pregnant. London: Food Standards Agency.

14. Vanderpump MP, Lazarus JH, Smyth PP, et al. (2011) Iodine status of UK schoolgirls: a cross-sectional survey. Lancet 377, 2007-2012.

15. Bath SC, Walter A, Taylor A, et al. (2014) Iodine deficiency in pregnant women living in the South East of the UK: the influence of diet and nutritional supplements on iodine status. Br J Nutr 111, 1622-1631.

16. Fowles ER (2002) Comparing pregnant women's nutritional knowledge to their actual dietary intake. MCN Am J Matern Child Nurs 27, 171-177.

17. Charlton KE, Gemming L, Yeatman H, et al. (2010) Suboptimal iodine status of Australian pregnant women reflects poor knowledge and practices related to iodine nutrition. Nutrition 26, 963-968.

18. Charlton K, Yeatman H, Lucas C, et al. (2012) Poor knowledge and practices related to iodine nutrition during pregnancy and lactation in Australian women: pre- and post-iodine fortification. Nutrients 4, 1317-1327.

19. Nithiananthan V, Carroll R \& Krebs J (2013) Iodine supplementation in pregnancy and breastfeeding: a New Zealand survey of user awareness. N Z Med J 126, 94-97.

20. Williamson C, Lean ME \& Combet E (2012) Dietary iodine: awareness, knowledge and current practice among midwives. Proc Nutr Soc 71, E142.

21. Gorstein J, Sullivan K, Parvanta I, et al. (2007) Indicators and Methods for Cross-Sectional Surveys of Vitamin and Mineral Status of Populations. The Micronutrient Initiative (Ottawa) and the Centers for Disease Control and Prevention. (Atlanta). http://www.who.int/vmnis/toolkit/ mcn-micronutrient-surveys.pdf. (accessed April, 2015).

22. COMA (1991) Dietary Reference Values for Food Energy and Nutrients for the United Kingdom. London: Report of the Panel on Dietary Reference Values of the Committee on Medical Aspects of Food Policy (COMA).

23. Moraveji M, Farmanbar R, Soleimannezhad N, et al. (2013) Knowledge and attitudes of people in Zanjan about iodine disorders. Researcher 5, 1-4.

24. Bougma K, Aboud FE, Harding KB, et al. (2013) Iodine and mental development of children 5 years old and under: a systematic review and meta-analysis. Nutrients $\mathbf{5}$, $1384-1416$

25. Velasco I, Carreira M, Santiago P, et al. (2009) Effect of iodine prophylaxis during pregnancy on neurocognitive development of children during the first two years of life. J Clin Endocrinol Metab 94, 3234-3241.

26. Bath SC, Sleeth ML, McKenna M, et al. (2014) Iodine intake and status of UK women of childbearing age recruited at the University of Surrey in the winter. Br J Nutr 112, 1715-1723.

27. Lampropoulou M, Lean M \& Combet E (2012) Iodine status of women of childbearing age in Scotland. Proc Nutr Soc 71, E143.

28. Andersson M, Karumbunathan V \& Zimmermann MB (2012) Global iodine status in 2011 and trends over the past decade. J Nutr 142, 744-750.

29. Fordyce F (2003) Database of the Iodine Content of Food and Diets Populated with Data from Published Literature. British Geological Survey Commissioned Report no. CR/03/84N. Keyworth, Nottingham: British Geological Survey.

30. Popa AD, Niţă O, Graur Arhire LI, et al. (2013) Nutritional knowledge as a determinant of vitamin and mineral supplementation during pregnancy. BMC Public Health 13, 1105. 
31. Melse-Boonstra A \& Jaiswal N (2010) Iodine deficiency in pregnancy, infancy and childhood and its consequences for brain development. Best Pract Res Clin Endocrinol Metab 24, 29-38.

32. Kibirige MS, Hutchison S, Owen CJ, et al. (2004) Prevalence of maternal dietary iodine insufficiency in the north east of England: implications for the fetus. Arch Dis Child Fetal Neonatal Ed 89, F436-F439.

33. Lazarus JH, Parkes AB, Smyth PPA, et al. (2005) Iodine status in early pregnancy: relation to thyroid function. In 13th International Thyroid Congress, Buenos Aires, Argentina. Thyroid Abstracts, vol. 15, pp. 218.

34. Barnett C, Visser T, Williams F, et al. (2002) Inadequate iodine intake of $40 \%$ of pregnant women from a region in Scotland. J Endocrinol Invest 25, 90.

35. Zimmermann $M$ \& Delange F (2004) Iodine supplementation of pregnant women in Europe: a review and recommendations. Eur J Clin Nutr 58, 979-984.

36. Cuco G, Fernandez-Ballart J, Sala J, et al. (2006) Dietary patterns and associated lifestyles in preconception, pregnancy and postpartum. Eur J Clin Nutr 60, 364-371.

37. Rifas-Shiman SL, Rich-Edwards JW, Willett WC, et al. (2006) Changes in dietary intake from the first to the second trimester of pregnancy. Paediatr Perinat Epidemiol 20, $35-42$.

38. Inskip HM, Crozier SR, Godfrey KM, et al. (2009) Women's compliance with nutrition and lifestyle recommendations before pregnancy: general population cohort study. BMJ 338, b481.

39. Crozier SR, Robinson SM, Godfrey KM, et al. (2009) Women's dietary patterns change little from before to during pregnancy. J Nutr 139, 1956-1963.

40. Haggarty P, Campbell DM, Duthie S, et al. (2009) Diet and deprivation in pregnancy. BrJ Nutr 102, 1487-1497.

41. Berti C, Decsi T, Dykes F, et al. (2010) Critical issues in setting micronutrient recommendations for pregnant women: an insight. Matern Child Nutr 6, Suppl. 2, 5-22.

42. Darmon N \& Drewnowski A (2008) Does social class predict diet quality? Am J Clin Nutr 87, 1107-1117.

43. Rasmussen LB, Ovesen L, Bulow I, et al. (2001) Evaluation of a semi-quantitative food frequency questionnaire to estimate iodine intake. Eur J Clin Nutr 55, 287-292.

44. Azar B (2000) A web of research: they're fun, they're fast and they save money, but do web experiments yield quality results? Monit Psychol 31, 42-47.

45. Brown A \& Arnott B (2014) Breastfeeding duration and early parenting behaviour: the importance of an infant-led, responsive style. PLOS ONE 9, e83893.
46. Alcalde MC (2011) 'To make it through each day still pregnant': pregnancy bed rest and the disciplining of the maternal body. J Gend Stud 20, 209-221.

47. Wellings K, Jones KG, Mercer CH, et al. (2013) The prevalence of unplanned pregnancy and associated factors in Britain: findings from the third National Survey of Sexual Attitudes and Lifestyles (Natsal-3). Lancet 382, 1807-1816.

48. McCance R \& Widdowson E (2002) McCance and Widdowson's The Composition of Foods. London: Food Standards Agency.

49. Skeaff SA (2009) Iodine nutrition in pregnancy: meeting iodine requirements in the diets of pregnant women. In Comprehensive Handbook of Iodine: Nutritional, Biochemical, Pathological and Therapeutic Aspects, pp. 1259-1264. Burlington, MA: Elsevier, Inc.

50. Athearn PN, Kendall PA, Hillers VV, et al. (2004) Awareness and acceptance of current food safety recommendations during pregnancy. Matern Child Health J 8, 149-162.

51. Becker DV, Braverman LE, Delange F, et al. (2006) Iodine supplementation for pregnancy and lactation - United States and Canada: recommendations of the American Thyroid Association. Thyroid 16, 949-951.

52. Andersson M, de Benoist B, Delange F, et al. (2007) Prevention and control of iodine deficiency in pregnant and lactating women and in children less than 2-years-old: conclusions and recommendations of the Technical Consultation. Public Health Nutr 10, 1606-1611.

53. Stagnaro-Green A, Sullivan S \& Pearce EN (2013) Iodine supplements during and after pregnancy - reply. JAMA 309, 1345-1346.

54. Bath SC, Jolly KB \& Rayman MP (2013) Iodine supplements during and after pregnancy. JAMA 309, 1345.

55. Bath SC, Button S \& Rayman MP (2014) Availability of iodised table salt in the UK - is it likely to influence population iodine intake? Public Health Nutr 17, 450-454.

56. Scientific Advisory Committee on Nutrition (2014) SACN Statement on Iodine and Health - 2014. SACN: Reports and Position Statements. https://www.gov.uk/government/ uploads/system/uploads/attachment_data/file/339439/SACN_ Iodine_and_Health_2014.pdf. (accessed April 2015).

57. Lucas C, Charlton KE \& Yeatman H (2014) Nutrition advice during pregnancy: do women receive it and can health professionals provide it? Matern Child Health $J \mathbf{1 8}$, 2465-2478.

58. Buckton C, Combet E \& Lean ME (2015) 'Language is the source of misunderstandings' - the impact of terminology on public perceptions of nutritional health promotion messages. Proc Nutr Soc $\mathbf{7 4}$ (OCE1), E10. 